\title{
Assessment of in-hand manipulation by occupational therapists in paediatric practices in South Africa
}

\author{
Annelize Kruger, B OT (UFS); M OT (UFS). https://orcid.org/0000-0002-7947-2929 \\ Post-graduate student / Private Practitioner.
}

\author{
Monique Strauss, B OT (UFS); M OT (UFS). https://orcid.org/0000-0003-2342-8889
}

Lecturer, Department of Occupational Therapy, Faculty of Health Sciences, University of the Free State, Bloemfontein, South Africa.

\section{* Marieta M, Visser, B OT (UFS); MSc OT (Wits). https://orcid.org/0000-0002-8825-4683}

Lecturer, Department of Occupational Therapy, Faculty of Health Sciences, University of the Free State, Bloemfontein, South Africa.

\section{Mariette Nel. BA (UFS); BA Hons (UFS); MMedSc (Biostatistics) (UFS). https://orcid.org/0000-0002-3889-0438}

Lecturer, Department of Biostatistics, Faculty of Health Sciences, University of the Free State, Bloemfontein, South Africa.

Introduction: Assessment of in-hand manipulation is fundamental to guide treatment for children with fine motor delays. Limited literature is available on how South African occupational therapists assess in-hand manipulation. This study aimed to describe which current in-hand manipulation assessment methods are used and what the preferences of occupational therapists in all areas of paediatric practices are regarding a suitable instrument.

Methods: Quantitative cross-sectional study design with a non-probability, purposive sampling method was used. Participants completed an EvaSys survey system online questionnaire.

Results: Two-hundred-and-ninety-two $(n=292)$ occupational therapists registered with the HPCSA participated. Limited familiarity $(n=50 ; 17.1 \%)$ with the formal assessment instruments described in literature was reported. The informal assessment methods most commonly used were subjective observation of tasks $(n=287 ; 98.3 \%)$ of scholastic tasks $(n=261 ; 89.4 \%)$ and play tasks ( $n=255$; $87.3 \%)$ for children between the ages of five to six years ( $n=273 ; 93.5 \%)$. Preferences supported a descriptive instrument accompanied by a user manual that is administered under 15 minutes, in multiple languages, and with attention to the quality of movements and compensatory techniques used by the child.

Conclusion: Results showed that the current and preferred assessment methods used by occupational therapists might provide guidance for the future development of a contextual, relevant in-hand manipulation instrument for paediatric practices in South Africa.

Keywords: in-hand manipulation; assessment methods; paediatric practice

\section{INTRODUCTION}

Assessment is the foundation from which occupational therapy interventions in all areas of practice are planned, improvement is measured, and effectiveness of therapeutic interventions are determined'. An occupational therapist working in paediatric practice may be consulted to determine the cause for poor hand function. This should include the assessment and treatment of poorly developed in-hand manipulation skills. In the context of paediatric practices, in-hand manipulation is inherently linked to the proficiency with which a child performs scholastic, self-care and play tasks ${ }^{2-5}$. Children with in-hand manipulation delays are often characterised as 'clumsy', with slow and messy fine motor skills $\mathbf{s}^{6,7}$, or they present with handwriting difficulties ${ }^{4,8,9}$.

During the assessment of the child's functional limitations, obtaining adequate and accurate information on in-hand manipulation by means of a suitable assessment instrument is vital, as this guides the intervention plan and ensures quality service delivery ${ }^{10}$. Instruments used for assessing in-hand manipulation in clinical practice have been described in the literature ${ }^{5,11-15}$. A review of these instruments, based on the Instrument Evaluation Framework of Rudman and Hannah ${ }^{16}$, was performed by the principal investigator. None of these instruments met all the criteria related to clinical utility, standardisation, purpose, psychometric properties, and the client's perspective required for hand function assessments ${ }^{17}$. Arguably, this could be the reason why therapists appear to assess in-hand manipulation informally by using checklists or clinical observations ${ }^{13}$. However, no research was found to substantiate these assumptions.

A survey conducted in $201 \mathrm{I}$ to determine how South African occupational therapists assessed poor handwriting in foundation phase learners, confirmed that in-hand manipulation is an intrinsic performance component of handwriting, which $84 \%$ of the therapists 'always' assessed. However, no elaboration on whether formal or informal assessment methods were used was provided ${ }^{18}$. In 2017 , a survey was conducted to determine the assessment instruments used by South African paediatric occupational therapists, which again made no reference to any hand function assessment instrument, 
including in-hand manipulation, that could guide the therapist's clinical reasoning process ${ }^{19}$. No literature on how occupational therapists in South Africa are assessing in-hand manipulation as well as no information describing the preferences of clinical therapists for a suitable in-hand manipulation assessment instrument at a grassroots level, was found. This demonstrates a gap in research in relation to the current clinical methods used by clinicians to assess the six components of in-hand manipulation, (namely finger-to-palm translation to achieve stabilisation, palm-to-finger translation, simple and complex shift, and simple and complex rotation). Moreover, understanding clinicians' preferences are required to select the most suitable in-hand manipulation assessment, or alternatively, inform the instrument development process in creating a new assessment instrument.

\section{LITERATURE REVIEW}

In-hand manipulation is the complex skill of adjusting an object using different movements of the fingers for more effective placement. It enables a child to handle and place items, such as shoelaces or puzzle pieces, with more precision ${ }^{2,20}$ as well as allowing an efficient pencil grasp needed for refined and controlled movements during drawing and writing ${ }^{8,21}$. The six components of in-hand manipulation as described by the Modified Classification System ${ }^{3}$, are finger-to- palm translation to achieve stabilisation, palm-to-finger translation, simple and complex shift, and simple and complex rotation. In addition, a component can also be performed 'with stabilisation', referring to (an) additional object(s) being held in the ulnar side of the palm ${ }^{3}$. Development starts after a child's first year until the age of twelve, when the components are performed similarly to an adult, albeit not at the same speed and with the same quality ${ }^{10,22}$.

Assessment methods for in-hand manipulation that occupational therapists use can be either formal or informal. To ensure that a test is appropriate for a clinical setting, the clinician should critically evaluate the purpose of the assessment and appropriateness for the intended population. Ideally, a formal method should include a norm- or criterion-referenced evaluation with established standardised procedures for administration and scoring determined according to a formal instrument development process, which includes evaluated psychometric properties ${ }^{16,23,24}$. The instruments described in the literature that have evidence of formal instrument development, include the UFS In-Hand Manipulation Checklist (UFS IHM-C) $)^{13,25}$, the In-hand Manipulation Test - Quality section $(\text { IMT-Q })^{6,26}$, Test of In-hand Manipulation (TIHM) ${ }^{4,27}$ that was refined into the TIHM-Revised (TIHM-R) ${ }^{12}$, the Observational Protocol of In-Hand Manipulation ${ }^{5,28}$, the unnamed test of Pehoski ${ }^{15,22}$, the Test of In-hand Manipulation Skills (TIMS) ${ }^{14}$, the unnamed test of Bonnier ${ }^{29}$, and the Timed-Test of In-Hand Manipulation (TIHM-T $)^{30}$. An occupational therapist can also use formal hand function assessments that include features of in-hand manipulation to guide their clinical observations. Examples include the naturalistic observational hand function Assessment of Children's Hand Skills (ACHS) $)^{31,32}$, and the pegboard-based Functional Dexterity Test (FDT) for children $^{33,34}$. These two instruments report only on dexterity or hand function as a whole and not on the specific in-hand manipulation components $^{3,35}$.

Informal in-hand manipulation assessment methods can provide a therapist with information about the child's performance, but the results are usually descriptive and cannot be compared to established norms or criteria. Informal assessments often include no evidence of instrument development or studies to support psychometric properties such as reliability or validity. This assess- ment method relies on the occupational therapist's judgment and skilled observations and as such, tends to be subjective ${ }^{23}$. Examples of informal methods of assessment include screening or observational 'checklists' and suggested screening activities that contain a section on in-hand manipulation skills expected for age groups which are available in Occupational Therapy for Children: $6^{\text {th }}$ ed (Table I0-I: pp. 296) ${ }^{36}$. The use of these screening activities and collateral information obtained from parents or teachers either in the form of an interview or questionnaire and observation of the child's participation in certain activities during school, play or self-care tasks, can help to determine the intensity and duration of the problematic areas related to poor in-hand manipulations ${ }^{37}$. This can guide a clinician towards determining whether therapy services or an in-depth evaluation are required. The documentation of in-hand manipulation observations, either by using clinical notes or video recordings ${ }^{14}$, can be combined with a self-designed checklist that can aid the assessor to quickly refer to the different in-hand manipulation components for more precise observations.

The use of skilled observations by the therapist remains invaluable in clinical settings where resources are limited. A clinician's choice of activities can be influenced by the availability of the resources in a clinical setting, such as the instrument or equipment (for example, toys and child-size furniture ${ }^{25}$ ). When assessing in-hand manipulation, the clinician should be mindful of the practical and contextual aspects that can influence the accuracy of the assessment results. The practical aspects include the method of documentation, as well as the resources of time and equipment available to the clinician. Documentation is an important aspect of the occupational therapy process and should adhere to the Health Professions Council of South Africa's (HPCSA) guidelines for patient records ${ }^{38}$. Different methods of record-keeping are permissible, provided it is done with precision to enable the accurate interpretation of both the assessment and reassessment results. Time constraints should also be considered, as this was a factor that influenced the lack of use of certain hand therapy assessment instruments by South African occupational therapists ${ }^{18}$.

The contextual aspects include the age of the child and how the child interacts with the activity demands of the assessment task, such as maintaining an interest in an appropriate task to motivate the child to engage optimally ${ }^{22,28}$. The manner in which the instructions are presented can also influence the performance of a child, as confirmed by Exner who suggested that when verbal and visual cues are provided, children perform better in the assessment ${ }^{39}$. It was therefore important to ascertain how occupational therapists in South Africa are navigating the practical and contextual aspects of the in-hand manipulation assessment.

The needs and preferences of clinicians in terms of instruments suited to their practice can be influenced by the following components: (i) the purpose of an instrument; (ii) the language and age ranges of the intended population; and (iii) the practical aspects on which components of in-hand manipulation can be scored, along with the instructions, time to administer and documentation format. Firstly, the purpose of an assessment can either be descriptive, predictive, evaluative or a combination of these. It guides the therapist in understanding what information to collect and how to interpret the results from the assessment, whether to determine the baseline of the child at that moment in time (descriptive), the future ability or outcome of the child (predictive), or the change that occurs in the child over time (evaluative) $)^{16,23}$. Secondly, as South Africa is a multilingual country with eleven national languages, of which isiZulu, followed by English and isiXhosa, are the most common languages 
spoken outside the household, isiZulu, isiXhosa and Afrikaans are the most commonly spoken languages at home ${ }^{40}$. This results in a multilinguistic challenge in paediatric practice, with possible differences between the languages of the therapist and that of the child. Thirdly, the instruments described in the literature have inconsistent scoring for aspects of in-hand manipulation with reference to quality of the movement ${ }^{14}$, speed of the movement ${ }^{30}$, the frequency with which the correct movement is repeated ${ }^{5}$, and the number of times an item is dropped ${ }^{22}$.

The aims of this study therefore were firstly to investigate the current methods used by South African occupational therapists in paediatric practices when assessing in-hand manipulation, and secondly, to determine their preferences in terms of a suitable inhand manipulation instrument.

\section{METHODS}

\section{Study design}

A quantitative, cross-sectional study was conducted to address the research aims.

\section{Sampling and population}

A non-probability, purposive sampling method ${ }^{24,41}$ was used to ensure that the sample was representative of the population of paediatric occupational therapists in South Africa. At the time of the study, 5 I I I occupational therapists were registered with the HPCSA, although the exact number of the population was unknown, as the HPCSA database provides no record of the practice settings in which the occupational therapists work $^{42}$. When the ratio of the Occupational Therapy Association of South Africa (OTASA) members working in paediatric practices $(73.5 \%)^{43}$ was applied to the HPCSA membership base, it was estimated that the population comprised of 3849 occupational therapists.

The inclusion criteria were therefore occupational therapists who currently worked in paediatric practices or had worked in paediatric practices within the past two years, were registered with the HPCSA, and who practised in South Africa for more than six months. The online questionnaire was distributed via email through the correspondence platform of OTASA, posting on the social media platforms, that included Facebook, WhatsApp, Instagram, Linked-in and using 'word-of-mouth'. Furthermore, the researcher applied for access to the HPCSA occupational therapists email dataset to distribute the questionnaire personally per email.

\section{Instrumentation}

Data were collected by means of an online questionnaire* via the EvaSys survey system, available in English and took on average 20 minutes to complete. The questionnaire was compiled from indicators found in literature and consisted of three sections. The first was to obtain demographic information of the participants and their practice profile. The second section focused on different assessment methods used by the participants. This included known in-hand manipulation tests as well as informal assessment methods. The third section was directed at the therapists' preferences for a suitable in-hand manipulation instrument based on some aspects listed in the Instrument Evaluation Framework ${ }^{16}$. In addition to each closed-ended questionnaire item, a non-compulsory 'other' open-ended option was provided to allow participants to elaborate on their answers to supplement the results.

*Contact the corresponding author for more information regarding the questionnaire.

\section{Pilot testing of the questionnaire}

Content validity of the questionnaire was established with five occupational therapists who were purposively contacted by the researcher based on their knowledge within the paediatric field and familiarity with questionnaires. These participants did not meet all the inclusion criteria of the study, specifically the criterion of having worked in a paediatric practice in the last two years. The pilot study participants provided feedback on the layout, structure, clarity, suitability, and the face validity of the questionnaire, upon which minimal editorial changes and no content changes were incorporated. They completed the questionnaire once the changes had been made to determine the ease of completion on different electronic devices. The pilot study data were excluded from the data analysis.

\section{Procedure}

In order to add to the rigor of the study the test-retest reliability of the questionnaire was also determined, and data were collected in two rounds. The first round aimed to recruit as many occupational therapists working in paediatric practices in South Africa as possible through different distribution methods. The link to the survey was available for six weeks. To limit the memory effect ${ }^{44}$, the second round only commenced ten days after participants completed the first round. Those who indicated their willingness to participate in the second round then received the link per email and the link remained open for 10 days. To promote a higher response rate and to limit nonresponsive errors, participants received reminder prompts and were given the option to participate in a continuing professional development (CPD) accredited activity after completing a questionnaire round.

\section{Data analysis}

Descriptive statistics, namely frequencies and percentages for categorical data, and medians and ranges for numerical data, were calculated from data obtained in Round I. Analysis of percentages for questions was completed for 292 participants. The percentages to the different options of a question might add up to more than a $100 \%$ when the participants could choose more than one answer or less than $100 \%$ for questions which could be omitted by participants.

Temporal stability of the questionnaire, namely "how constant scores remain from one occasion to another" 41 was determined to evaluate test-retest reliability. The reliability analysis for the two datasets was compared by means of a $2 \times 2$ table for each question. When questions had a conflicting percentage score of more than $20 \%$ for an answer, the question was considered unreliable and excluded from further analysis ${ }^{45}$. A total of 19 questions and 45 sub-questions that tested unreliable were excluded from the final data set.

\section{*Ethical considerations}

Ethical approval for this study was obtained from the Health Sciences Research Ethics Committee of the University of the Free State (reference UFS-HSD2018/0358/2905). The participants were informed about the study and gave informed consent prior to the start of the questionnaire. If the participant did not meet the inclusion criteria, further access to the questionnaire was denied. Participants' information was kept strictly confidential throughout the course of the study and securely stored on a password-protected laptop.

*Ethical approval for this study was granted prior to the enactment of the amended POPIA on 2I-07-0I. 
Table I: Demographic profile of participants $(n=292)$

\begin{tabular}{|c|c|c|}
\hline \multicolumn{2}{|l|}{ Variables } & Median (range) \\
\hline \multicolumn{2}{|l|}{ Age of participants } & $31(23-66)$ \\
\hline \multirow[t]{2}{*}{ Experience } & $\begin{array}{l}\text { Years working as } \\
\text { an occupational } \\
\text { therapist }\end{array}$ & $9(I-45)$ \\
\hline & $\begin{array}{l}\text { Years working in } \\
\text { paediatric practice }\end{array}$ & $7(I-46)$ \\
\hline & & n (\%) \\
\hline \multirow[t]{2}{*}{ Gender } & Female & $284(97.3)$ \\
\hline & Male & $8(2.7)$ \\
\hline \multirow{4}{*}{$\begin{array}{l}\text { Highest Occupational } \\
\text { Therapy qualification* }\end{array}$} & Diploma & $2(0.7)$ \\
\hline & Bachelor's degree & $252(86.3)$ \\
\hline & Master's degree & $31(10.6)$ \\
\hline & Doctoral degree & $2(0.7)$ \\
\hline \multirow[t]{3}{*}{ Employment status } & Full-time & $217(74.3)$ \\
\hline & Part-time & $63(21.6)$ \\
\hline & $\begin{array}{l}\text { Unemployed/leave } \\
\text { of absence }\end{array}$ & $12(4.1)$ \\
\hline \multirow{10}{*}{$\begin{array}{l}\text { Practice setting } \\
\text { (participants could } \\
\text { choose more than one } \\
\text { answer) }\end{array}$} & Private practice & $145(49.7)$ \\
\hline & $\begin{array}{l}\text { Pre-school/Early } \\
\text { childhood develop- } \\
\text { ment centre }\end{array}$ & $135(46.2)$ \\
\hline & Primary school & $135(46.2)$ \\
\hline & Hospital & $87(29.8)$ \\
\hline & Special needs school & $74(25.3)$ \\
\hline & Community clinic & $26(8.9)$ \\
\hline & $\begin{array}{l}\text { Non-profit organisa- } \\
\text { tion }\end{array}$ & $25(8.7)$ \\
\hline & Secondary school & $20(6.9)$ \\
\hline & Tertiary institution & $12(4.1)$ \\
\hline & Rehabilitation centre & $9(3.1)$ \\
\hline \multirow{3}{*}{$\begin{array}{l}\text { Paediatric client profile } \\
\text { (participants could } \\
\text { choose more than one } \\
\text { answer) }\end{array}$} & Toddlers ( $\mathrm{I}-3$ years) & $179(61.3)$ \\
\hline & $\begin{array}{l}\text { Pre-schoolers (4-6 } \\
\text { years) }\end{array}$ & $264(90.4)$ \\
\hline & $\begin{array}{l}\text { Primary school } \\
\text { (7-12 years) }\end{array}$ & $233(79.8)$ \\
\hline
\end{tabular}

*Missing data relate to participant(s) with Doctoral degree in another field (I), and honours degree (2) and a business degree (I)

\section{RESULTS}

Of the 30I participants that opened the questionnaire link, 9 participants did not meet the inclusion criteria so did not complete the questionnaire, while 292 participants continued and completed the first round. The response rate in relation to the population of 5 I II occupational therapists registered with HPCSA at the time of the study, was $5.7 \%$. However, when adjusted to the proposed population of 3849 occupational therapists working in paediatric practices, an acceptable overall response rate of $7.6 \%$ was observed, which compared well to similar surveys performed on the same population ${ }^{19}$ and similar online survey methods ${ }^{46,47}$. Of the
Table II: Formal assessment methods used $(n=292)$

\begin{tabular}{|c|c|c|}
\hline \multirow{2}{*}{ Instrument } & Familiarity & Reported use \\
\hline & n (\%) & n (\%) \\
\hline $\begin{array}{l}\text { UFS In-hand Manipulation- } \\
\text { Checklist (UFS IHM-C) }\end{array}$ & $15(5.1)$ & $6(2.1)$ \\
\hline $\begin{array}{l}\text { Test of In-hand Manipulation } \\
\text { (TIHM) }\end{array}$ & $13(4.5)$ & $3(1.0)$ \\
\hline $\begin{array}{l}\text { In-hand Manipulation Test } \\
\text { (IMT-Q) }\end{array}$ & $9(3.1)$ & $4(1.4)$ \\
\hline $\begin{array}{l}\text { Test of In-hand Manipulation - } \\
\text { Revised (TIHM-R) }\end{array}$ & $8(2.7)$ & $\mathrm{I}(0.3)$ \\
\hline $\begin{array}{l}\text { Observation Protocol on In- } \\
\text { Hand Manipulation }\end{array}$ & $7(2.4)$ & $4(1.4)$ \\
\hline $\begin{array}{l}\text { Test of In-hand Manipulation } \\
\text { Skills (TIMS) }\end{array}$ & $5(1.7)$ & $I(0.3)$ \\
\hline Unnamed Test of Pehoski & $3(1.0)$ & $0(0.0)$ \\
\hline $\begin{array}{l}\text { Functional Dexterity Test for } \\
\text { children (FDT) }\end{array}$ & $17(5.8)$ & $6(2.1)$ \\
\hline $\begin{array}{l}\text { Assessment of Children's Hand } \\
\text { Skills (ACHS) }\end{array}$ & $5(1.7)$ & $2(0.7)$ \\
\hline $\begin{array}{l}\text { Screening Activities for Hand } \\
\text { Skills (Occupational Therapy } \\
\text { for Children } 6^{\text {th }} \text { Edition, Table } \\
(0-1)\end{array}$ & $28(9.6)$ & $20(6.8)$ \\
\hline
\end{tabular}

292, 167 participants (54.2\%) completed the second round which determined the test-retest reliability of the questionnaire.

\section{Demographic profile}

Participants' demographic information is shown in Table I (adjacent). The practice profile comprised the practice setting, and type of clients seen by the participants.

The expertise of the participants was confirmed by their qualifications, wide age range and years of experience. Among the participants that held a Master's degree, five (16.1\%) completed their Master's in Early Childhood Intervention. Most participants worked on a full-time basis $(n=217 ; 74.3 \%)$ and predominantly in the private practice setting $(n=145 ; 49.7 \%)$ with a client profile that consisted primarily of pre-schoolers $(n=264 ; 90.4 \%)$.

\section{Current in-hand manipulation assessment methods}

The results of the assessment methods used were grouped into two categories, namely the familiarity and reported use of formal assessment instruments (Table II, above), and the results of the informal assessment methods used (Table III, pI5). The practical and contextual aspects are presented in Tables IV (pI5) and V (pI5) respectively.

\section{Formal assessment methods}

Participants indicated whether they were familiar with the listed instruments. If they indicated yes, more questions followed to determine the specific instrument(s) they were familiar with and/ or used. Table II illustrates the degree of familiarity and reported use of the seven in-hand manipulation assessment instruments, the two complementary hand function assessments, and the guidelines for screening activities sourced from the literature.

Most of the participants $(n=242 ; 82.9 \%)$ indicated that they were not familiar with any of the listed formal assessment methods. Of the remaining 50 (17.1\%) that indicated their familiarity ${ }^{28}$, 
Table III: Informal assessment methods $(n=292)$

\begin{tabular}{|c|l|}
\hline Informal assessment methods & $\mathrm{n}(\%)$ \\
\hline Collateral information & - \\
\hline Self-designed teacher interview/questionnaire & $94(32.2)$ \\
\hline Standardised teacher interview/questionnaire & $4(1.4)$ \\
\hline Checklist & $74(25.3)$ \\
\hline Self-designed & $20(6.8)$ \\
\hline Standardised & $3(1.0)$ \\
\hline Skilled observation & $287(98.3)$ \\
\hline Scholastic tasks & $26 \mathrm{I}(89.4)$ \\
\hline Drawing or colouring & $254(87.0)$ \\
\hline Writing or copying & $248(84.6)$ \\
\hline Cutting & $247(84.6)$ \\
\hline Play task & $255(87.3)$ \\
\hline Threading activity & $235(80.5)$ \\
\hline Self-care task & $160(54.8)$ \\
\hline
\end{tabular}

Table IV: Practical aspects of current assessment used $(n=292)$

\begin{tabular}{|l|l|l|}
\hline \multirow{2}{*}{ Practical aspects of assessment } & $\mathrm{n}(\%)$ \\
\hline \multirow{2}{*}{$\begin{array}{l}\text { Documentation } \\
\text { method }\end{array}$} & Clinical notes & $268(91.8)$ \\
\cline { 2 - 3 } & Video recording & $33(11.3)$ \\
\hline \multirow{2}{*}{ Reassess } & Yes & $237(81.2)$ \\
\cline { 2 - 3 } & No & $55(18.8)$ \\
\hline \multirow{2}{*}{$\begin{array}{l}\text { Administration } \\
\text { time }\end{array}$} & $0-5$ minutes & $73(25.0)$ \\
\cline { 2 - 3 } & $30-45$ minutes & $12(4.1)$ \\
\cline { 2 - 3 } Scoring time & $45-60$ minutes & $3(1.0)$ \\
\cline { 2 - 3 } & $0-15$ minutes & $262(89.7)$ \\
\hline \multirow{2}{*}{$\begin{array}{l}\text { Resources avail- } \\
\text { able }\end{array}$} & Yes & $30(10.3)$ \\
\cline { 2 - 3 } & No & $256(87.7)$ \\
\hline
\end{tabular}

(9.6\%), indicated that the Screening Activities of Hand Skills guideline described by Exner in the Occupational Therapy for Children 6th Edition textbook was the most familiar to participants, followed by an additional fine motor assessment, the FDT for children $(n=17$; $5.8 \%$ ), and the in-hand manipulation assessment, UFS IHM-C, developed in South Africa by Visser et al. ${ }^{13,25}(n=15,5.1 \%)$. However, for all the instruments, there were fewer responses of their reported use in comparison to the familiarity indicated.

\section{Informal assessment methods}

An overview of the informal assessment methods used, namely collateral information, checklists and skilled observations by the participants was obtained using a cascading mechanism, built into the questionnaire so that once one of the main questions were selected, subsequent questions followed from which the participant could choose (Table III, above).

Collateral information obtained from teachers consistently showed that 94 (32.2\%) participants used a self-designed questionnaire, with fewer reporting the use of a standardised questionnaire. Checklists were used by $74(25.3 \%)$ participants. Of the three main informal methods, skilled observations during tasks $(n=287$;
Table V: Contextual aspects of current assessment used $(\mathbf{n}=\mathbf{2 9 2})$

\begin{tabular}{|c|c|c|}
\hline \multicolumn{2}{|c|}{ Contextual aspects of assessment } & $\mathrm{n}(\%)$ \\
\hline \multirow[t]{4}{*}{ Age groups } & $1-2$ years & $91(31.2)$ \\
\hline & $5-6$ years & $273(93.5)$ \\
\hline & $7-8$ years & $234(80.1)$ \\
\hline & $11-12$ years & $12 \mid(4 \mid .4)$ \\
\hline \multirow{2}{*}{$\begin{array}{l}\text { Change activity } \\
\text { demands in relation } \\
\text { to the child's age }\end{array}$} & Yes & $278(95.2)$ \\
\hline & No & $14(4.8)$ \\
\hline \multirow[t]{2}{*}{$\begin{array}{l}\text { Presentation of } \\
\text { instructions }\end{array}$} & $\begin{array}{l}\text { After presenting the task, a } \\
\text { verbal instruction to only use } \\
\text { the specific hand that is being } \\
\text { assessed }\end{array}$ & $69(23.6)$ \\
\hline & $\begin{array}{l}\text { Actively discourage the use of } \\
\text { the hand not being assessed by } \\
\text { asking the child to hold onto a } \\
\text { fixed object }\end{array}$ & $24(8.2)$ \\
\hline \multirow[t]{5}{*}{$\begin{array}{l}\text { Position of the child } \\
\text { during assessment }\end{array}$} & $\begin{array}{l}\text { Seated at a child-sized table } \\
\text { where the child's feet can } \\
\text { touch the ground }\end{array}$ & $232(79.5)$ \\
\hline & $\begin{array}{l}\text { On the floor, seated cross- } \\
\text { legged }\end{array}$ & $21(7.2)$ \\
\hline & $\begin{array}{l}\text { Seated at an adult-sized table, } \\
\text { feet not touching the ground }\end{array}$ & $6(2.1)$ \\
\hline & In a standing position & $3(1.0)$ \\
\hline & $\begin{array}{l}\text { On the floor, lying on their } \\
\text { stomach }\end{array}$ & $\mathrm{I}(0.3)$ \\
\hline
\end{tabular}

98.3\%) was the reported method mostly used. In that method, scholastic tasks $(\mathrm{n}=26 \mathrm{I} ; 89.4 \%)$, closely followed by play tasks $(n=255 ; 87.3 \%)$ and self-care tasks $(n=160 ; 54.8 \%)$, were the commonly observed tasks. From these tasks, the specific activities observed included cutting $(n=247 ; 84.6 \%)$, drawing/colouring $(n=254 ; 87 \%)$, writing/copying $(n=248 ; 84.9 \%)$, and threading activities $(n=235 ; 80.5 \%)$.

\section{Practical aspects of an assessment}

The practical aspects related to the clinical utility of the assessments included the time taken to administer and score the assessment followed by the documentation method used and whether a reassessment was performed, as well as the availability of resources in the clinical setting to assess a child's in-hand manipulation, are summarised in Table IV (adjacent).

The most commonly used documentation method was clinical notes, as reported by 268 (91.8\%) participants, while 33 (I I.3\%) used video recordings. Most of the participants $(n=237 ; 81.2 \%)$ reported reassessing in-hand manipulation of the child. For the administration time, $25.0 \%(n=73)$ indicated they used only $0-5$ minutes. Similarly, for the scoring time, the shortest period of 0-15 minutes was indicated by $262(89.7 \%)$ of the participants. When the participants were asked to indicate if they had access to available resources to assess in-hand manipulation in children, 256 $(87.7 \%)$ responded in the affirmative. The open-ended option that followed this question prompted the participants to elaborate on their responses. The responses were analysed and showed that the majority used familiar objects, such as pegboards ( $n=6 I ; 20.9 \%)$, beads $(n=39 ; 13.4 \%)$, money or coins $(n=37 ; 12.7 \%)$, clay or similar mouldable material $(n=37 ; 12.7 \%)$ and pegs $(n=35 ; 12.0 \%)$. 
Table VI: Preferences for a suitable in-hand manipulation assessment instrument

\begin{tabular}{|c|c|c|}
\hline \multicolumn{2}{|c|}{ Preferences for a suitable assessment tool } & \multirow{2}{*}{$\begin{array}{l}n(\%) \\
255(87.3)\end{array}$} \\
\hline \multirow[t]{4}{*}{$\begin{array}{l}\text { Purpose of } \\
\text { assessment* }\end{array}$} & $\begin{array}{l}\text { Identify the child's strengths } \\
\text { and limitations in order to } \\
\text { inform the clinical treatment } \\
\text { plan }\end{array}$ & \\
\hline & $\begin{array}{l}\text { Describe the child's current } \\
\text { functional status }\end{array}$ & $243(83.2)$ \\
\hline & $\begin{array}{l}\text { Evaluate the change in } \\
\text { functioning over time and } \\
\text { monitor the progress made by } \\
\text { the child }\end{array}$ & $216(74.0)$ \\
\hline & Predict the child's future ability & $80(27.4)$ \\
\hline \multirow[t]{3}{*}{$\begin{array}{l}\text { User manual } \\
\text { inclusions* }\end{array}$} & $\begin{array}{l}\text { Scoring and interpretation } \\
\text { instructions }\end{array}$ & $284(97.3)$ \\
\hline & Administration instructions & $282(96.6)$ \\
\hline & Equipment instructions & $228(78.1)$ \\
\hline \multirow{2}{*}{$\begin{array}{l}\text { Scorable in-hand } \\
\text { manipulation } \\
\text { aspects }\end{array}$} & Quality of movement & $250(85.6)$ \\
\hline & Compensatory techniques used & $244(83.6)$ \\
\hline \multirow[t]{2}{*}{ Method of scoring } & $\begin{array}{l}\text { Score according to criteria per } \\
\text { item }\end{array}$ & $238(81.5)$ \\
\hline & Video clips to guide scoring & $5 \mathrm{I}(17.5)$ \\
\hline \multirow[t]{3}{*}{ Administration time } & $0-5$ minutes & $51(17.5)$ \\
\hline & $30-45$ minutes & $9(3.1)$ \\
\hline & $45-60$ minutes & $2(0.7)$ \\
\hline \multirow[t]{2}{*}{ Scoring time } & $0-15$ minutes & $272(93.2)$ \\
\hline & $15-30$ minutes & $20(6.8)$ \\
\hline \multirow{5}{*}{$\begin{array}{l}\text { Presentation } \\
\text { language }\end{array}$} & English & $287(98.3)$ \\
\hline & Afrikaans & $153(52.4)$ \\
\hline & isiZulu & $63(21.6)$ \\
\hline & Sesotho & $56(19.2)$ \\
\hline & isiXhosa & $45(15.4)$ \\
\hline
\end{tabular}

*Participants could select all options that applied.

\section{Contextual aspects of an assessment}

Results of the contextual aspects that a clinician should consider when using an assessment of in-hand manipulation are the different age groups of children assessed, if the activity demands were changed in relation to the child's age, the manner in which the instructions were presented, and lastly, the position of the child during which in-hand manipulation was assessed (Table V, p I5).

The majority of the participants $(n=273 ; 93.5 \%)$ indicated that they assessed in-hand manipulation for 5-6-year-old children.

When asked if the tasks' demands or selection of equipment were changed in relation to the child's age, 278 (95.2\%) participants responded in the affirmative. Regarding how the presentation of instructions were provided, only a few of the respondents $(23.6 \%$ and $8.2 \%$ ) indicated which methods were used in practice. Most of the participants $(n=232 ; 79.5 \%)$ indicated that they assessed a child's in-hand manipulation while the child was seated at a childsized table where the child's feet could touch the ground. Some indicated a more informal approach where the child sat cross-legged on the floor $(n=21 ; 7.2 \%)$.

Preferences for a suitable in-hand manipulation instrument The preferences indicated by the participants regarding an in-hand manipulation instrument included the purpose of the assessment, what should be included in a user manual, the aspects of in-hand manipulation which should be included in the scoring, as well as the scoring method, the time to administer and score, and the language of presentation of the assessment instrument (Table VI, adjacent).

For the purpose of a suitable instrument, both the descriptive and the evaluative components to monitor a child's progress through the change that occurs over time, were indicated as preferable by the majority of participants. The preferred aspects to be included in a user manual that received a high response rate were the need for scoring and interpretation instructions $(n=284$; $97.3 \%)$, followed by administration instructions $(n=282 ; 96.6 \%)$. Fewer participants indicated the need for equipment instructions $(n=228 ; 78.1 \%)$. With regard to the scorable aspects, the majority of participants had a clear preference for scoring the quality of the in-hand manipulation movement and compensatory techniques used by the child. Most of the participants preferred to score according to a specific criterion for an item, while the use of video clips to guide the scoring was supported by $5 \mathrm{I}$ participants (I7.5\%). A preferred administration and scoring time for the shortest time slot was consistently seen, with only a few indicating the longer time slots.

The majority of the participants preferred that an instrument be presentable in English $(n=287 ; 98.3 \%)$. Additional suggestions included the use of a technological platform (for example, a tablet to enable visual demonstrations or an audio track) to present the instructions to children with intellectual impairments or who are hard of hearing, along with the proposal to provide specific instructions in all the languages in written or audio format.

\section{DISCUSSION}

The first aim of this study was to determine the current assessment methods for in-hand manipulation used by occupational therapists. Demographics were representative of paediatric occupational therapists in South Africa ${ }^{19}$. Clinical expertise on the different developmental phases of in-hand manipulation was confirmed since the majority of children treated by the participants were between three and six years old, which corresponds with the period of rapid development for in-hand manipulation ${ }^{3}$.

The limited familiarity with published in-hand manipulation instruments might be due to the participants' perception that in-hand manipulation was too insignificant an aspect of fine motor skills to warrant further investigation, while also revealing to what extent participants engaged with the scientific literature of the profession. This was inferred as the reason why the available in-hand manipulation instruments were not further investigated. When participants did consult primary literature, this included familiar sources such as the guideline for Screening Hand Skills described in the Occupational Therapy for Children textbook. Furthermore, their familiarity with the UFS IHM-C, which was published in the South African Journal of Occupational Therapy (SAJOT) $)^{13,25}$ attested to participants accessing research published locally.

The lower response rate regarding 'used methods' observed in relation to familiarity could be suggestive of two interrelated factors. Firstly, most of the instruments are still in the process of being developed, lack comprehensive and commercially available manuals, and no form of training is provided. These factors limit the application of 
the instrument to the clinical setting, as well as the awareness created by marketing strategies, such as the catalogues distributed online or at workshops. Secondly, these results may confirm the findings of Pitout ${ }^{47: 5}$ that "although occupational therapists value research, they do not engage in applying research in practice". This situation persists even though the use of a formal in-hand manipulation instrument, when applicable, is preferable as it ensures that the clinicians' clinical decisions are based on rational and defensible results while ensuring evidence-based practices are upheld ${ }^{23}$.

Informal assessment methods remain clinically useful and invaluable to a clinician. This study confirmed that observation of occupation-based activities is the primary assessment method used by participants $(n=287,98.3 \%)$. However, should observations be unstructured and unsupported by the literature, the inferences drawn would be subjective and less reliable. In comparison, skilled and systematic observations (based on the comprehensive Modified Classification System of In-hand Manipulation ${ }^{3}$ ) which are documented in detail, set the foundation for making useful interpretations. The use of checklists $(n=74 ; 25.3 \%)$ and collateral information from teachers in the form of interviews or self-designed questionnaires $(n=94 ; 32.2 \%)$ are rarely used but valuable to the assessment process. A possible explanation for the infrequent use of these methods as pointed out in another South African study ${ }^{18}$ relates to the tendency to use information obtained from the teacher, which is additional information on the child's context, influenced by the therapists' age and years of experience, which varied widely in this study.

Scholastic tasks are highly regarded $(n=261,89.4 \%)$ and correspond with the findings that most of the collateral information was obtained from teachers $(n=98 ; 33.6 \%)$, as well as with the two age groups that were assessed most often, namely children between the ages of five and seven. Since these age groups are largely concerned with refining pre-writing skills in Grade $\mathrm{R}$ and learning writing skills in Grade ${ }^{18,48}$, it follows naturally that the activities of cutting, drawing/colouring and writing/copying were those most readily observed from the scholastic tasks. When considering that $60 \%$ of a school-going child's day is concerned with the fine motor task of writing ${ }^{18}$, it is understandable that practitioners focus on these tasks, specifically when poor in-hand manipulation is suspected. The activity of cutting provides a good opportunity to observe the simple shift movement of the supporting hand as the fingers adjust the paper for cutting ${ }^{2,4}$. In-hand manipulation required to adjust writing utensils includes both complex and simple rotation when correctly orientating the pencil, and complex shift when positioning the fingers on the shaft of the pencil or crayon ${ }^{3,14}$. However, to comprehensively establish the degree of in-hand manipulation delay, difficulties in other aspects of a child's functionality should also be considered, such as play and self-care tasks.

Participation in play tasks, per definition, requires a child to use toys, equipment, and supplies appropriately'. Of the various play activities listed, threading was indicated by most participants $(n=235 ; 80.5 \%)$ as the preferred activity for observing in-hand manipulation. Threading is an ideal task for observing simple shift of the one hand, while performing translation movements of the beads held in the other hand. However, this activity is only included in the $\mathrm{ACHS}^{31,32}$ and not in any of the other specific in-hand manipulation instruments. The availability of resources in clinical settings was confirmed in this study, with specific reference to play items, such as pegboards, beads, coins and clay. These can be used to observe in-hand manipulation and are included as items by the IMT-Q6, $\mathrm{TIMS}^{14}$, and the UFS IHM-C ${ }^{13}$. Furthermore, the use of pegboards and pegs were also included by various other in-hand manipulation instruments ${ }^{11-14,22,30,49}$, with differences in the exact sizes, numbers of pegs and methods of presenting the task to the child. As pegboards are accessible and familiar items in practice settings, including this item in an assessment for in-hand manipulation is justifiable and relevant. Nevertheless, it is not advised to only use a pegboard, as in-hand manipulation should be displayed with a variety of items, and skills with one type of object are not always associated with an ability to transfer said skill to another size or shape of object ${ }^{10,14}$. The limited tasks indicated by participants which are used when observing in-hand manipulation during play and self-care tasks in this study however, highlight the need to train clinicians on how to correctly present and observe in-hand manipulation during these familiar tasks.

Self-care tasks include activities of daily living that are directed towards taking care of one's own body'. Various self-care activities were noted by approximately half of the participants $(n=160$; $54.8 \%$ ) as suitable for observing in-hand manipulation, although these tasks are not commonly included in developmentally based in-hand manipulation instruments. However, while the Observation Protocol of In-hand manipulation ${ }^{5}$ includes one task of buttoning and unbuttoning a shirt, the occupation-based assessment $A C H S^{31,32}$ includes several activities of daily living through which a child can spontaneously demonstrate the use of in-hand manipulation (although it is not guaranteed that all the isolated components of in-hand manipulation are assessed during these occupation-based activities). These occupation-based instruments allow for the identification of critical occupational performance components caused by hand skill difficulties in the relevant environment ${ }^{31,50}$, and are criterion-referenced when formally developed. In comparison, all the other current formal in-hand manipulation instruments follow a developmental assessment approach where the main focus is to identify the specific underlying components to determine a developmental delay in a more structured environment and tend to be norm-referenced ${ }^{51}$.

Using clinical notes to accurately document assessment findings, as reported by most participants, is important to improve interpretation of the reassessment findings and can provide valuable evidence when reviewed to generate practice-based evidence ${ }^{52}$. Using video recordings to document the in-hand manipulation movements performed by a child has been advised by the IMT- $\mathrm{Q}^{6}$, UFS IHM-C ${ }^{13}$ and $\mathrm{TIMS}^{14}$, but was reportedly used by only a small number of participants $(n=33 ; 11.3 \%)$. This method can ensure that the refined and subtle movements of in-hand manipulation are accurately observed and can be a valuable aid to monitor progress and compare to the results of the reassessment. Moving from written notes to electronic notes can incorporate the safe inclusion of video recordings, while also simplifying the retrieval of patient records for future research ${ }^{52}$.

Changing the activity demands in relation to the child's age, as indicated by nearly all the participants $(n=278 ; 95.2 \%)$, is encouraging as a child's best performance can be observed when they are interested and invested in succeeding at a task. During informal observations, the task can be changed intuitively while ensuring that the desired movement is still elicited; for example, changing the picture that a child is asked to colour in or a game that requires the throw of a dice. Still, these observations of a child, without a reference to an age norm or criterion requirements, remain descriptive and problematic when planning interventions. For a formal standardised assessment to accurately measure a child's abilities, different tasks or adjusting the requirements of a task should be 
age-appropriate yet uniform. Examples are available, such as the tasks of the Miller Assessment of Pre-schoolers (MAP) $)^{53}$ that make allowances for different items per age group.

The two presentation methods that were consistently used by the participants encourage the child to only use the dominant hand while restricting the use of the other, which is similar to the assessment instructions of the unnamed test of Pehoski ${ }^{22,54}$, $\mathrm{TIHM}^{49}$ and TIHM-R ${ }^{12}$. It was encouraging that the majority of the therapists ensured that the child was positioned at a table where their feet could touch the ground $(n=232 ; 79.5 \%)$, as this position best enables the child to display their in-hand manipulation skills in comparison to sitting at an adult-sized table ${ }^{26}$. Although no research has been done that opposes the child sitting crosslegged on the floor, as indicated by 21 (7.2\%) participants, the impact of this assessment position should be further investigated as it might allow the therapist to observe the child in a more naturalistic setting.

The second objective of this study was to determine the participants' preferences for a suitable in-hand manipulation instrument. The findings indicated that a suitable instrument should incorporate all the elements of a descriptive instrument, with elements of evaluative instruments. For the user manual inclusions, the need for scoring and interpretation instructions ( $n=284 ; 97.3 \%$ ) was emphasised, more so than for equipment instructions $(n=228 ; 78.1 \%)$. Since in-hand manipulation is a complex skill, the inclusion of training by means of video clips with a detailed scoring form would be most suitable, which has been recommended by the IMT-Q6 and ACHS55. However, at the time of this study, this training has not yet realised. The two scorable aspects of in-hand manipulation that were preferred included the quality of the movement and the compensatory techniques used. Two assessments, the TIMS which clearly distinguishes between the quality of the movements on a 4-point rating scale ${ }^{14}$ and the UFS IHM-C which includes a comprehensive list of possible compensatory techniques that the child might use per task, align with this preference ${ }^{13,25}$.

From the other practical aspects relating to an assessment, it was evident that participants preferred a quick instrument. Those instruments that require more time to administer, such as the IMT-Q6, "' and TIMS ${ }^{14}$ that take 20-30 minutes, might therefore be less suitable in a South African context. A definite preference was indicated that the instrument be developed in English $(n=287$, $98.3 \%$ ). However, equally valuable was the strong support and suggestions to include other South African languages, either in the written form for a translator or as pre-recorded instructions, which could even include sign-language. Translation and crosscultural adaptation of measurement instruments, as per the steps outlined by the COSMIN ${ }^{56}$, should form part of the instrument development process to strengthen its reliability and validity.

The unanimity among the participants relating to the preferences of a suitable instrument stood in contrast to the first set of questions relating to the current methods used. This marked awareness among the participants of what would suit the practice setting and highlights the need for further research to strongly consider these preferences as design principles when choosing or developing an instrument for the South African paediatric practice context.

\section{Strengths and limitations}

This study used a non-probability, purposive sampling method with the intention of representing the clinical practices and latent knowledge held by South African occupational therapists experienced in working in paediatric practices. The results of the study were strengthened by the wider sampling population that was deliberately approached and the adequate response rate ${ }^{19,45,46}$, which provides valuable information that can be used towards further instrument development for the assessment of in-hand manipulation. However, the results cannot be generalised to other assessment practices relating to other aspects, apart from in-hand manipulation.

The questionnaire was detailed and could be completed in a relative short time since it consisted of predominantly closed-ended questions. To minimise a low-response rate, the questionnaire was presented online so that participants with time constraints were able to conveniently access and complete the questionnaire, with the added encouragement of accessing a CPD-accredited activity upon completion.

The results of questions that did not test reliable were excluded from the study and warrant further investigation. A respondent error was observed by a participant who provided a contradiction in the maximum age range of their years of experience, as indicated in Table I ( $\mathrm{p}$ |4), which was included to remain true to the data received.

The questionnaire used the formal in-hand manipulation instruments known to the researcher at the time of this study. In the interim, the researcher became aware of three instruments that were not included in the questionnaire, namely the unnamed test of Bonnier ${ }^{29}$ published in 2006, the T-TIHM ${ }^{30}$ published in 20I5, and the TIHM-M ${ }^{57}$ published in 2019, which could be seen as another limitation.

\section{RECOMMENDATIONS}

Clinicians are encouraged to apply the in-hand manipulation instruments described in published literature. It is recommended that practice-based evidence be generated by accurate documentation that includes the use of electronic clinical notes. These notes can include secure storage of video clip recordings of the child's hand while performing in-hand manipulation in an age-appropriate task, and should incorporate the use of different items, not only pegboards.

Educators are recommended to provide future training in refining the observational skills of in-hand manipulation by occupational therapists during occupation-based activities, specifically during self-care and play tasks. This training can either occur at undergraduate or postgraduate level through workshops or interactive online courses.

Further research in the development of an in-hand manipulation instrument that is contextually appropriate for South Africa and has evaluated psychometric properties ${ }^{16,17}$ is recommended, as observations alone cannot be used when planning intervention for this component of complex fine motor skills.

Obtaining a broader understanding of how the other hand function components are assessed by occupational therapists in South Africa is recommended. This will provide a better perspective of the South African practice context and generate practice-based knowledge from this practice area.

\section{IMPLICATIONS}

The implications of the preferences supported the development of a predominantly descriptive instrument, with attention to scoring the quality of in-hand manipulation movements and compensatory techniques used by the child. This instrument should include a 
comprehensive user manual that is administered under I 5 minutes, in multiple languages.

\section{CONCLUSIONS}

This study set out to describe the current and preferred methods used by South African occupational therapists in paediatric practices when assessing in-hand manipulation. The limited familiarity with and sparse use of formal assessment instruments are concerning. Subjective observations of occupation-based tasks were the most commonly used informal assessment methods. Checklists and collateral information obtained from teachers were used to a lesser degree. Practically, participants mentioned using clinical notes to document their assessment with a few using video recordings that are supported by the literature.

The detailed overview provided by this study uniquely contributed to a better understanding of the clinical practices of in-hand manipulation assessment at grassroots level. The findings of this study clearly recommended the provision of more training and guidance on how to assess in-hand manipulation. The further development of an instrument that is contextually relevant and standardised is recommended, to reflect the current and preferred assessment methods used by the occupational therapists in paediatric practice in South Africa.

\section{Acknowledgements}

Dr. Daleen Struwig, medical writer/editor, Faculty of Health Sciences, University of the Free State, for technical and editorial preparation of the manuscript.

\section{AUTHOR CONTRIBUTIONS}

This article was submitted by Annelize Kruger as part of her dissertation for Masters in Occupational Therapy at the University of the Free State. Monique Strauss and Marieta Visser supervised the study and assisted in the writing of the article. Mariette Nel was the biostatistician who analysed the data. All the authors approved the final version of the article submitted.

\section{REFERENCES}

1. American Occupational Therapy Association. Occupational Therapy Practice Framework: domain and process. 3rd ed. American Journal of Occupational Therapy. 2017;68(Suppl I): SI. http://dx.doi.org//0.5014/ajot.2014.682006

2. Pehoski C. Object manipulation in infants and children. In: Henderson SE, Pehoski C, editors. Hand Function in the Child: Foundations for Remediation. 2nd ed. Maryland, MO: Mosby Elsevier Inc.; 2006: 143-160. https://doi.org/10.1016/b978-0-323-03186-8.x500 I-I

3. Pont K, Wallen M, Bundy A. Conceptualising a modified system for classification of in-hand manipulation. Australian Occupational Therapy Journal. 2009;56(I):2-15.

http://dx.doi.org/10.1 I I I/j. I440-1630.2008.00774.x

4. Cornhill $\mathrm{H}$, Case-Smith J. Factors that relate to good and poor handwriting. American Journal of Occupational Therapy. 1996;50(9):732739. http://dx.doi.org//0.5014/ajot.50.9.732

5. Humphry R, Jewell K, Rosenberger RC. Development of in-hand manipulation and relationship with activities. American Journal of Occupational Therapy. 1995;49(8):763-771.

http://dx.doi.org/10.50I4/ajot.49.8.763

6. Exner CE. Content validity of the in-hand manipulation test. American Journal of Occupational Therapy. 1993;47(6):505-513.

http://dx.doi.org// 0.5014/ajot.47.6.505
7. Case-Smith J. The relationships among sensorimotor components, fine motor skill, and functional performance in preschool children. American Journal of Occupational Therapy. 1995;49(7):645-652. http://dx.doi.org// 0.50I4/ajot.49.7.645

8. Feder KP, Majnemer A, Bourbonnais D, Platt R, Blayney M, Synnes A. Handwriting performance in preterm children compared with term peers at age 6 to 7 years. Developmental Medicine and Child Neurology. 2005;47(3): 163-170.

https://doi.org/10.1 I I I/j. I469-8749.2005.tb0 I I 10.x

9. Brown T, Link J. The association between measures of visual perception, visual-motor integration, and in-hand manipulation skills of school-age children and their manuscript handwriting speed. British Journal of Occupational Therapy. 2016;79(3):163-171. http://dx.doi.org/I0.1 I77/0308022615600179

10. Exner CE. Evaluation and interventions to develop hand skills. In: Case-smith J, O'Brien JC, editors. Occupational Therapy for Children. $6^{\text {th }}$ ed. Maryland, MO: Mosby Elsevier Inc.; 2010: 275-324.

II. Miles Breslin DM, Exner CE. Construct validity of the in-hand manipulation test: a discriminant analysis with children without disability and children with spastic diplegia. American Journal of Occupational Therapy. 1999;53(4):38I-386. https://doi.org/10.5014/ajot.53.4.38I

12. Pont K, Wallen M, Bundy A, Case-Smith J. Reliability and validity of the test of in-hand manipulation in children ages 5 to 6 years. American Journal of Occupational Therapy. 2008;62(4):384-392. http://dx.doi.org// 0.50I4/ajot.62.4.384

13. Visser M, Nel M, du Plessis C, et al. In-hand manipulation (IHM) in children 6 and 7 years of age: a follow-up study. South African Journal of Occupational Therapy. 2016;46(2):52-58. http://dx.doi.org/10.17159/2310-3833/2016/v46n2a9

14. Raja K, Katyal P, Gupta S. Assessment of in-hand manipulation: tool development. International Journal of Health and Allied Sciences. 2016;5(4):235. http://dx.doi.org/10.4I03/2278-344X.194092

15. Pehoski C, Henderson A, Tickle-Degnen L. In-hand manipulation in young children: translation movements. American Journal of Occupational Therapy. 1997;5I(9):719-728. http://dx.doi.org/I0.50I4/ajot.5I.9.719

16. Rudman D, Hannah S. An instrument evaluation framework: Description and application to assessments of hand function. Journal of Hand Therapy. 1998; I I (4):266-277. http://dx.doi.org/I0.1016/S0894-II30(98)80023-9

17. Kruger A, Strauss M, Visser M, Nel R. Assessment of in-hand manipulation by occupational therapists in paediatric practices in South Africa [Master's thesis]. Bloemfontein: University of the Free State; 2020.

18. Van der Merwe J, Smit N, Vlok B. A survey to investigate how South African occupational therapists in private practice are assessing and treating poor handwriting in foundation phase learners: Part I - Demographics and assessment practices. South African Journal of Occupational Therapy. 201 I;4I(3):3-II.

19. Janse van Rensburg E, Johnson C, Rawlins C, et al. Describing the use of assessments by occupational therapists in paediatric practice in South Africa. Unpublished undergraduate study. Bloemfontein: University of the Free State; 2017.

20. Exner CE. Development of hand function. In: Case-smith J, Allen A, Pratt P, editors. Occupational Therapy for Children. 3rd ed. St. Louis, MO: Mosby Elsevier Inc.; 1995: 268-306.

21. Denton PL, Cope S, Moser C. The effects of sensorimotor-based intervention versus therapeutic practice on improving handwriting performance in 6- to $1 \mathrm{I}$-year-old children. American Journal of Occupational Therapy. 2006;60(1):16-27. 
http://dx.doi.org/10.5014/ajot.60.1.16

22. Pehoski C, Henderson A, Tickle-Degnen L. In-hand manipulation in young children: rotation of an object in the fingers. American Journal of Occupational Therapy. 1997;5 I (7):544-52. http://dx.doi.org/10.5014/ajot.51.7.544

23. Laver Fawcett A. Principles of Assessment and Outcome Measurement for Occupational Therapists and Physiotherapists: Theory, Skills and Application. West Sussex, UK: John Wiley \& Sons Ltd.; 2007.

24. Kielhofner G. Research in Occupational Therapy: Methods of Inquiry for Enhancing Practice. Philadelphia, PA: F.A. Davis Company; 2006.

25. Visser M, Nel M, de Vries J, Klopper E, Olen K, van Coller J. In-hand manipulation of children aged four and five-years-old: translation, rotation and shift movements, in Bloemfontein. South African Journal of Occupational Therapy. 2014;44(2):22-28.

26. Smith-Zuzovsky N, Exner CE. The effect of seated positioning quality on typical 6- and 7-year-old children's object manipulation skills. American Journal of Occupational Therapy. 2004;58(4):380-8. http://dx.doi.org// 0.50I4/ajot.58.4.380

27. Case-Smith J. Fine motor outcomes in preschool children who receive occupational therapy services. American Journal of Occupational Therapy. 1996;50(I):52-61.

http://dx.doi.org/10.5014/ajot.50.1.52

28. Jewell K, Humphry R. Reliability of an observation protocol on inhand manipulation and functional skill development. Phys Occup Ther Pediatr. 1993; 13(3):67-82. http://dx.doi.org//0.1080/J006v13n03_06

29. Bonnier B, Eliasson A-C, Krumlinde-Sundholm L. Effects of constraint-induced movement therapy in adolescents with hemiplegic cerebral palsy: A day camp model. Scand J Occup Ther.

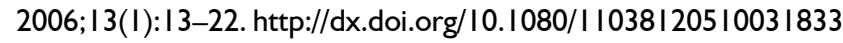

30. de Vries L, van Hartingsveldt MJ, Cup EHC, Nijhuis-van der Sanden MWG, de Groot IJM. Evaluating fine motor coordination in children who are not ready for handwriting: which test should we take? Occup Ther Int. 2015;22(2):6I-70. http://dx.doi.org/ I0. I002/oti. I 385

31. Chien CW, Brown T, McDonald R. A framework of children's hand skills for assessment and intervention. Child Care Health Dev. 2009;35(6):873-84. http://dx.doi.org/10.1 I II/j.1365-2214.2009.01002.x

32. Chien CW, Brown T, McDonald R. Examining construct validity of a new naturalistic observational assessment of hand skills for preschool- and school-age children. Aust Occup Ther J. 2012;59(2): 10820. http://dx.doi.org/I0. I I I /j. I440-1630.20 I2.00997.x

33. Lee-Valkov PM, Aaron DH, Eladoumikdachi F, Thornby J, Netscher DT. Measuring normal hand dexterity values in normal 3-, 4-, and 5 -year-old children and their relationship with grip and pinch strength. J Hand Ther. 2003;16(I):22-8.

http://dx.doi.org/10.1016/S0894-I I30(03)80020-0

34. Gogola GR, Velleman PFP., Xu S, Morse AM, Lacy B, Aaron D. Hand dexterity in children: administration and normative values of the Functional Dexterity Test. J Hand Surg Am. 20 13;38(I2):2426-31. http://dx.doi.org/10.1016/j.jhsa.2013.08.123

35. Klymenko G, Liu KPY, Bissett M, Fong KNK, Welage N, Wong RSM. Development and initial validity of the in-hand manipulation assessment. Aust Occup Ther J. 2018;65(2): I-II. http://dx.doi.org//0.1 I I I/1440-1630.12447

36. Case-Smith J, O'Brien JC. Occupational Therapy for Children. 6th ed. Missouri: Elsevier Mosby; 2010.

37. Stewart KB. Purposes, processes, and methods of evaluation. In: Case-Smith J, O'Brien P, editors. Occupational Therapy for Children. 6th Edit. USA: Elsevier Inc; 2010: 193-215.

38. Health Professions Council of South Africa (HPCSA). Guidelines for good practice in the health care professions: guidelines on the keeping of patient records.

https://www.hpcsa.co.za/Uploads/Professional_Practice/Conduct\%20\%26\%20Ethics/Booklet\%209\%20Keeping\%20of\%20 Patient\%20Records\%20September\%20\%202016.pdf (accessed 25 June 2020).

39. Exner CE. The zone of proximal development in in-hand manipulation skills of non-dysfunctional 3- and 4-year-old children. American Journal of Occupational Therapy. 1990;44(10):884-891.

http://dx.doi.org/10.5014/ajot.44.10.884

40. South African Government. South Africa's people. https://www.gov.za/about-sa/south-africas-people (accessed 29 June 2020).

4I. McMillan JH, Schumacher S. Research in education: evidence-based inquiry. 6th ed. Boston: Pearson Education Inc.; 2006.

42. Daffue Y. RE: Data Supply Request - for Registered Occupational Therapy practitioners - elizabethamalan@gmail.com. 2018, February 22.

43. Kietzmann A. RE: Master's study - Request for OTASA/SAISI/INSTOPP membership information - elizabethamalan@gmail.com. 2018, April 8.

44. DeVellis RF. Scale development: theory and applications. 4th ed. Los Angeles: Sage; 2017.

45. Hattingh Z, Le Roux M, Nel M, Walsh C. Assessment of the physical activity, body mass index and energy intake of HIV-uninfected and HIV-infected women in Mangaung, Free State province. South African Fam Pract. 2014;56(3): 196-200. http://dx.doi.org//0.1080/20786204.2014.936663

46. Gee BM, Devine N, Werth A, Phan V. Paediatric occupational therapists' use of sound-based interventions: a survey study. Occup Ther Int. 2013;20(3): I55-162. http://dx.doi.org/10.1002/oti. I 354

47. Pitout $H$. Research orientation of South African occupational therapists. South African J Occup Ther. 2013;43(2):5-II.

48. Van Hartingsveldt MJ, Cup EHC, Hendriks JCM, de Vries L, de Groot IJM, Nijhuis-van der Sanden MWG. Predictive validity of kindergarten assessments on handwriting readiness. Res Dev Disabil. 2015; 36:1 14-124. http://dx.doi.org/10.1016/j.ridd.2014.08.014

49. Case-Smith J. Effectiveness of school-based occupational therapy intervention on handwriting. American Journal of Occupational Therapy. 2002;56(I): 17-25. http://dx.doi.org//0.50I4/ajot.56.I.I 7

50. Chien CW, Brown T, McDonald R. Examining content validity and reliability of the Assessment of Children's Hand Skills (ACHS): A preliminary study. American Journal of Occupational Therapy. 2010;64(5):756-767. http://dx.doi.org/10.5014/ajot.2010.08158

5I. Bazyk S, Case-Smith J. School-based occupational therapy. In: CaseSmith J, editor. Occupational Therapy for Children. 6th ed. Missouri: Mosby Elsevier Inc.; 2010: 713-743.

52. Buchanan H, Jelsma J, Siegfried N. Practice-based evidence: Evaluating the quality of occupational therapy patient records as evidence for practice. South African Journal of Occupational Therapy. 2016;46(I):65-73. http://dx.doi.org//0.17159/2310-3833/2016/v46n la / 3

53. Miller LJ. Miller Assessment for Pre-schoolers: MAP manual. Revised Ed. San Antonio: TX; 1988.

54. Exner CE. Clinical interpretation of "in-hand manipulation in young children: translation movements." American Journal of Occupational Therapy. 1997;5I(9):729-732.

http://dx.doi.org/10.5014/ajot.51.9.729

55. CHSA Hub. Children's Hand Skills Assessment Hub 2016. 
http://childrenhandskills.com/ (accessed 29 June 2020).

56. Beaton, DE, Bombardier, C, Guillemin, F, Ferraz, MB. Guidelines for the process of cross-cultural adaptation of self-report measures. Spine, 2000;25(24):3186-3191.

https://doi.org/10.1097/00007632-200012150-00014

57. Kaiser, M, Carrascob, CA. Reliability of the Modified In-hand Manipulation Test and the Relationship Between In-hand Manipulation and Handwriting. Iranian Rehabilitation Journal, 20I9; 17(3):279-284. http://dx.doi.org// 0.32598/irj. I7.3.279

Corresponding Author:

*Marieta M. Visser

Email: vissermm@ufs.ac.za 